\title{
Intracerebral Hemorrhage in a Patient with Untreated Rheumatoid Arthritis: Case Report and Literature Review
}

\author{
Omar Kousa ${ }^{1}$, Dana H. Awad ${ }^{1}$, Yousif M. Hydoub ${ }^{2}$, Rasha Awawdeh ${ }^{3}$, Venkata Andukuri ${ }^{1}$ \\ 1. Internal Medicine, Creighton University Medical Center, Omaha, USA 2. Internal Medicine, Al-Mafraq Hospital, Abu \\ Dhabi, ARE 3. Internal Medicine, Al-Mafraq Hospital, Dubai, ARE
}

Corresponding author: Omar Kousa,mr.koosaa2009@hotmail.com

\begin{abstract}
Rheumatoid vasculitis (RV) occurs in patients with long-standing rheumatoid arthritis (RA) or high levels of immunological factors and can result in devastating cardiovascular (CV) events. Here we report a case of a 38-year-old male who presented with hypertensive emergency and intracerebral hemorrhage (ICH). In the literature, a few observational studies have indicated the association of RA with hypertension; however, little evidence exists supporting a direct relationship between RA and ICH. In this case, we attempted to evaluate the complex relationship between all of these factors and found that early detection and treatment of RA may be beneficial in reducing ICH; however, large studies in the future are warranted to validate our observation.
\end{abstract}

Categories: Internal Medicine, Neurology, Rheumatology

Keywords: rheumatoid arthritis (ra), intracerebral hemorrhage (ich), rheumatoid vasculitis(rv), hypertensive emergency

\section{Introduction}

Rheumatoid arthritis (RA) is a common, multisystem, autoimmune inflammatory disease. Despite the complexity of the disease, cardiovascular (CV) mortality remains the most common cause of death [1]. Although rheumatoid vasculitis (RV) is a known entity, it usually occurs in the setting of long-standing RA or with high levels of anti-citrullinated protein (anti-CCP) antibodies and rheumatoid factor (RF) [2]. The pathogenesis of vasculitis involves several mechanisms, one of which is immune-complex deposition in the sub-endothelium of affected vessels, a mechanism that may be augmented in patients with high levels of RF. Vasculitis has consistently been shown to be a major CV risk factor and it has also been hypothesized that systemic inflammation augments the effect of traditional CV risk factors, such as hypertension (HTN), lipids diseases and smoking, thereby increasing the risk of $\mathrm{CV}$ mortality and morbidity [3, 4]. However, central nervous system vasculitis in RA is rare. The literature contains only a few case reports on intracranial arteritis presenting as intracerebral hemorrhage (ICH) [5]. We aim, with this case report, to discuss the

Received 07/03/2019 Review began 07/11/2019 Review ended 07/15/2019 Published 07/19/2019

๑) Copyright 2019 Kousa et al. This is an open access article distributed under the terms of the Creative Commons Attribution License CC-BY 3.0., which permits unrestricted use, distribution, and reproduction in any medium, provided the original author and source are credited. complex relationship between RA, hypertension and ICH, suggesting that early detection and treatment of $\mathrm{RA}$ is beneficial in reducing this risk.

\section{Case Presentation}

A 38-year-old male of Southeast Asian descent presented to the emergency department with a sudden onset of weakness of the left limb that lasted for four hours as well as a mild generalized headache with no alarming symptoms. He had no other symptoms of end-organ damage. He had been diagnosed with essential hypertension one year prior to presentation and was being treated using $25 \mathrm{mg}$ of hydrochlorothiazide and was fairly controlled on that. Prior to admission, he did not suffer from any hypertensive retinopathy, nephropathy or hypertensive heart disease. His family history was unremarkable. On examination, his blood pressure (BP) was found to be elevated (160/110 $\mathrm{mmHg}$ ) with no orthostatic changes. His other vital signs were within the normal range. An initial neurological examination revealed a muscle power of 3/5 in the left upper and lower limbs. He had 4+ deep tendon reflexes on the left side. The results of the remaining examination were normal. Funduscopic examination showed no papilledema or hypertensive retinopathy. Plain computed tomography (CT) of the brain (Figure 1) showed intra-cerebral hemorrhage. After a neurosurgical assessment, he was deemed suitable for non-operative conservative management, and he was admitted to the intensive care unit (ICU) and treated with intravenous labetalol. No further neurological deficit developed, and he was shifted to the general medical ward after 36 hours of monitoring in the ICU. 


\section{Cureus}
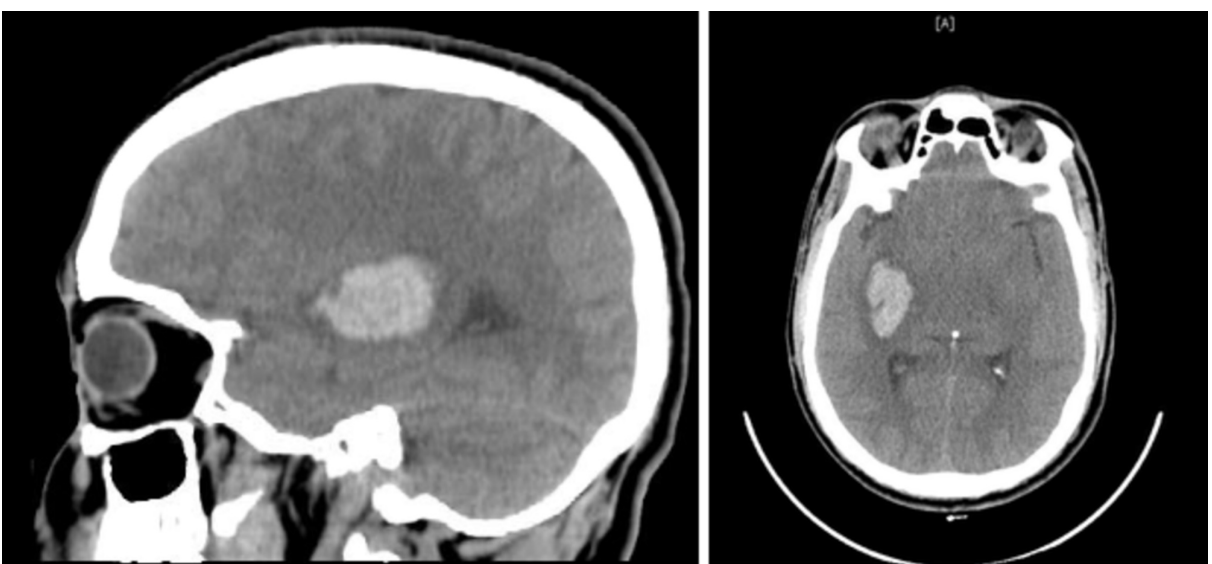

FIGURE 1: Computed tomography (CT) of the brain showing "a deep frontal lobe cerebral hemorrhage, mainly affecting the insula and involving the posterior limb of the internal capsule, with extrinsic compression of the ipsilateral thalamus."

On further questioning, the patient complained of joints pain, mainly involving the metacarpophalangeal and proximal interphalangeal joints and wrists bilaterally, which started six months prior and had worsened over three weeks prior to admission. He also reported shoulder and knee arthralgia. He reported aching and stiffening of his hands, wrists, and shoulder joints that would be partially relieved after taking a hot shower. He had sought medical attention for the joint symptoms and was given nonsteroidal anti-inflammatory drugs, with no definitive diagnosis or indication for further evaluation and follow-up in the clinic.

An extensive examination of his joints showed tenderness and synovitis, bilaterally, including two to four of the proximal interphalangeal and metacarpophalangeal, wrists and shoulder joints. He had no skin manifestations or rheumatoid nodules.

\section{Investigations}

Laboratory investigations (Table 1) showed an elevated erythrocyte sedimentation rate and platelet count. The levels of RF and anti-CCP were significantly elevated (185 IU/ml and 117 units/ml, respectively). X-rays of hands and feet (Figures 2-4) showed no bony abnormalities. Workup for secondary causes of hypertension, including hyperaldosteronism, Cushing's disease, pheochromocytoma and renal artery stenosis, was negative. An electrocardiogram showed borderline left ventricular hypertrophy that was not present in a previous electrocardiogram obtained one year prior. A transthoracic echocardiogram showed normal systolic function and confirmed borderline left ventricular hypertrophy (Figure 5). A CT angiogram of the brain was performed, which revealed no sign of vasculitis.

\begin{tabular}{|c|c|c|}
\hline & Result & Normal range \\
\hline Sodium & $141 \mathrm{mmol} / \mathrm{l}$ & $135-145 \mathrm{mmol} / \mathrm{l}$ \\
\hline Potassium & $3.4 \mathrm{mmol} / \mathrm{l}$ & $3.4-5.1 \mathrm{mmol} / \mathrm{l}$ \\
\hline Chloride & $101 \mathrm{mmol} / \mathrm{l}$ & 98-107 mmol/l \\
\hline Carbon dioxide & $27 \mathrm{mmol} / \mathrm{l}$ & $22-29 \mathrm{mmol} / \mathrm{l}$ \\
\hline Creatinine & $0.95 \mathrm{mg} / \mathrm{dL}$ & $0.7-1.2 \mathrm{mg} / \mathrm{dL}$ \\
\hline Urea & $8.9 \mathrm{mg} / \mathrm{dL}$ & $<23$ mg/dL \\
\hline Aldosterone standing & $0.33 \mathrm{nmol} / \mathrm{l}$ & $0.14-0.86 \mathrm{nmol} / \mathrm{l}$ \\
\hline Renin standing & $>128 \mathrm{nmol} / \mathrm{I}$ & $4-37.52 \mathrm{nmol} / \mathrm{I}$ \\
\hline Aldosterone supine & $0.33 \mathrm{nmol} / \mathrm{l}$ & $0.08-0.44 \mathrm{nmol} / \mathrm{l}$ \\
\hline Renin supine & $>128 \mathrm{nmol} / \mathrm{l}$ & 4-23.7 nmol/l \\
\hline Estimated glomerular filtration rate & $1 / \mathrm{min} / 1.73 \mathrm{~m}^{2}$ & $>60 \mathrm{ml} / \mathrm{min} / 17.3 \mathrm{~m}^{2}$ \\
\hline
\end{tabular}




\section{Cureus}

\begin{tabular}{|c|c|c|}
\hline Total urine volume & $2.7 \mathrm{~L}$ & $0.8-2.0 \mathrm{~L}$ \\
\hline Urine metanephrine level every $24 \mathrm{~h}$ & $1410 \mathrm{nmol} / 24 \mathrm{~h} / \mathrm{l}$ & $666-3691 \mathrm{nmol} / 24 \mathrm{~h}$ \\
\hline White blood cell & $9.81 \times 10^{9} / I$ & $4-11 \times 10^{9}$ \\
\hline Red blood cell & $5.1 \times 10^{12} / /$ & $4.3-5.7 \times 10^{9}$ \\
\hline Hemoglobin & $133 \mathrm{~g} / \mathrm{l}$ & $132-177 \mathrm{~g} / \mathrm{l}$ \\
\hline Hematocrit & 0.424 & $0.34-0.49$ \\
\hline Platelet & $468 \times 10^{9} / 1$ & $140-450 \times 10^{9}$ \\
\hline ESR & 101,80 & $1-13$ \\
\hline Prothrombin time & $13.4 \mathrm{~s}$ & $11.5-14.5 \mathrm{sec}$ \\
\hline International normalized ratio & 1.02 & $0.82-1.2$ \\
\hline Activated prothrombin time & $35.7 \mathrm{~s}$ & $28.6-38.2 \mathrm{sec}$ \\
\hline DRVV screen & 1.18 & $\leq 1.2$ \\
\hline LUPUS INTERP & Negative & - \\
\hline PTT-LA & $40.1 \mathrm{~s}$ & $29-45 \mathrm{~s}$ \\
\hline Antinuclear antibody & Negative & \\
\hline Cytoplasmic antineutrophil cytoplasmic antibodies & $<2 \mathrm{RU} / \mathrm{m}$ & $\leq 20 \mathrm{RU} / \mathrm{m}$ \\
\hline Perinuclear anti-neutrophil cytoplasmic antibodies & $<2 \mathrm{RU} / \mathrm{m}$ & $\leq 20 \mathrm{RU} / \mathrm{m}$ \\
\hline Complement 3 & $1.59 \mathrm{~g} / \mathrm{l}$ & $0.9-1.8 \mathrm{~g} / \mathrm{L}$ \\
\hline Complement 4 & $0.28 \mathrm{~g} / \mathrm{l}$ & $0.1-0.4 \mathrm{~g} / \mathrm{L}$ \\
\hline Cardiolipin IgG & 3.7 units & $\leq 10$ units $/ \mathrm{mL}$ \\
\hline Cardiolipin IgM & 1.00 units & $\leq 7$ units $/ \mathrm{mL}$ \\
\hline Cyclic citrullinated peptide antibodies & 117 units $/ \mathrm{mL}$ & $\leq 5$ units $/ \mathrm{mL}$ \\
\hline Anti-double-stranded DNA & $<10.0 \mathrm{RU}$ & $\leq 100 \mathrm{RU} / \mathrm{mL}$ \\
\hline Extractable nuclear antigens & Negative & - \\
\hline Rheumatoid factor & $185 \mathrm{IU} / \mathrm{ml}$ & $<14 \mathrm{lU} / \mathrm{ml}$ \\
\hline B2 glycoprotein immunoglobulin G & 3 units $/ \mathrm{ml}$ & $<5 \mu \mathrm{g} / \mathrm{ml}$ \\
\hline B2 glycoprotein immunoglobulin M & 1 units $/ \mathrm{ml}$ & $<5 \mu \mathrm{g} / \mathrm{ml}$ \\
\hline Low-density lipoprotein & $135 \mathrm{mg} / \mathrm{dL}$ & $0-100 \mathrm{mg} / \mathrm{dL}$ \\
\hline High-density lipoprotein & $20 \mathrm{mg} / \mathrm{dL}$ & $35-77 \mathrm{mg} / \mathrm{dL}$ \\
\hline Cholesterol & $244 \mathrm{mg} / \mathrm{dL}$ & $<205 \mathrm{mg} / \mathrm{dL}$ \\
\hline Triglyceride & $70 \mathrm{mg} / \mathrm{dL}$ & $<90 \mathrm{mg} / \mathrm{dL}$ \\
\hline Parathyroid hormone & 3.1 & $1.6-6.9 \mathrm{pmol} / \mathrm{l}$ \\
\hline Calcium & 2.21 & $2.2-2.55 \mathrm{mmol} / \mathrm{l}$ \\
\hline TSH & 1.5 & $0.27-4.2$ milli IU/I \\
\hline Free tri-iodothyronine & 4.2 & $3.1-6.8 \mathrm{pmol} / \mathrm{l}$ \\
\hline Free Thyroxin & 15 & $12-22 \mathrm{pmol} / \mathrm{l}$ \\
\hline Early morning cortisol & 12 & $10-22 \mu \mathrm{g} / \mathrm{dl}$ \\
\hline
\end{tabular}

TABLE 1: Laboratory results.

ESR: Erythrocyte sedimentation rate; TSH: Thyroid-stimulating hormone. 


\section{Cureus}

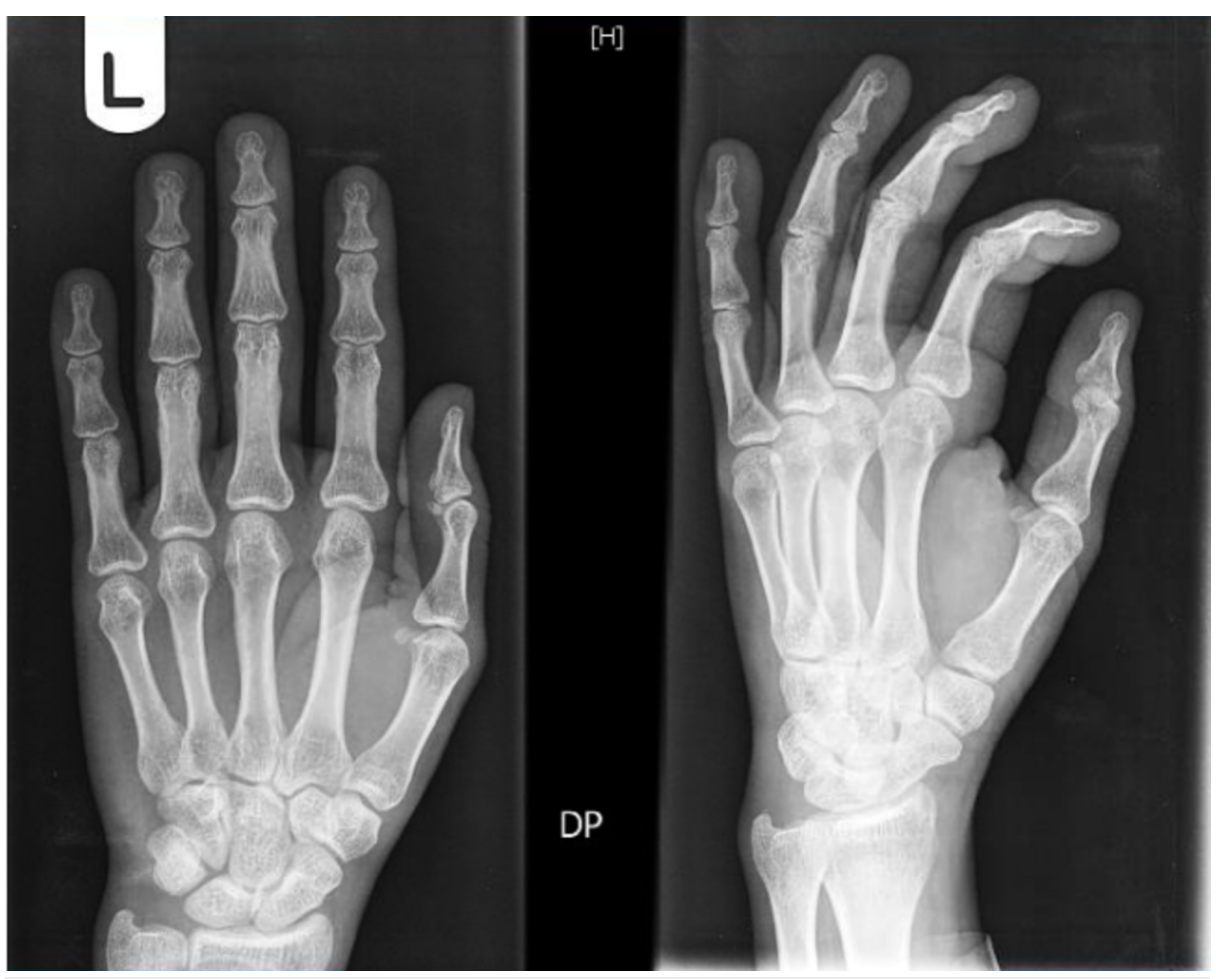

FIGURE 2: X-ray of the left hand showing "no bony abnormality, evidence of erosive arthropathy, or fracture or dislocation." 


\section{Cureus}

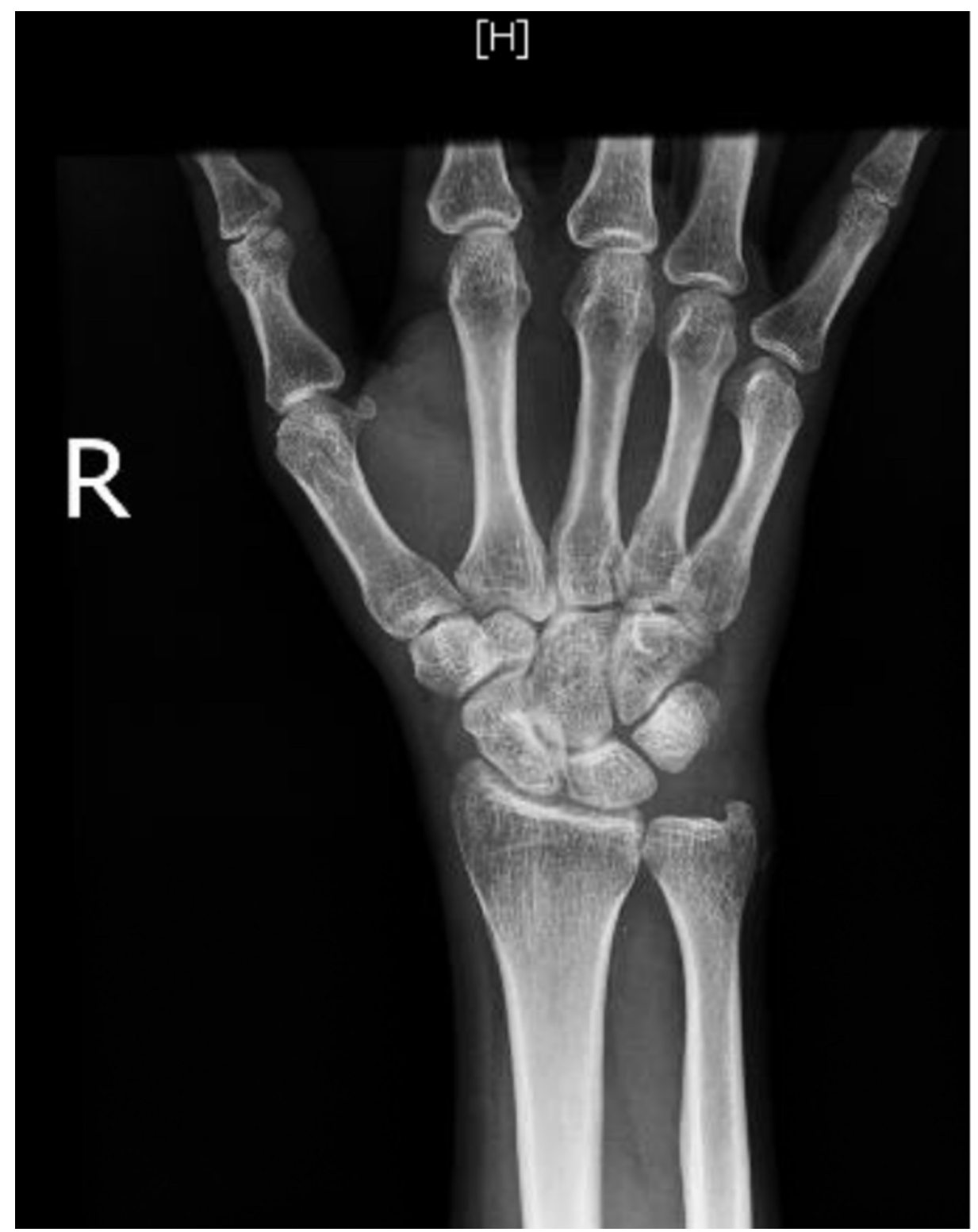

FIGURE 3: X-ray of the right hand showing "no bony abnormality, evidence of erosive arthropathy, or fracture or dislocation." 


\section{Cureus}
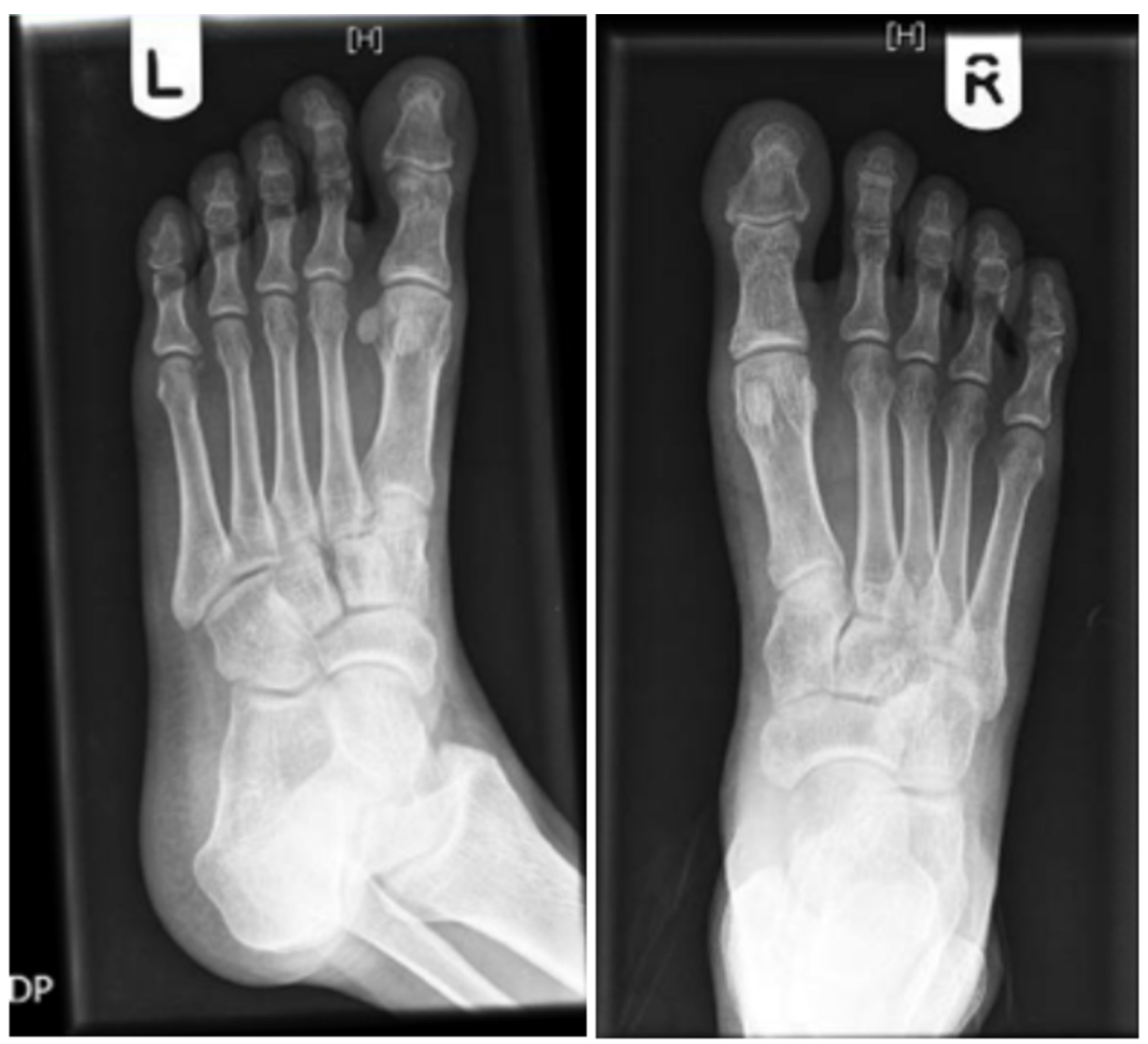

FIGURE 4: X-ray of the feet (the left foot and right foot are indicated by (L) and (R) on the top, respectively) showing "no bony abnormality, evidence of erosive arthropathy, or fracture or dislocation."

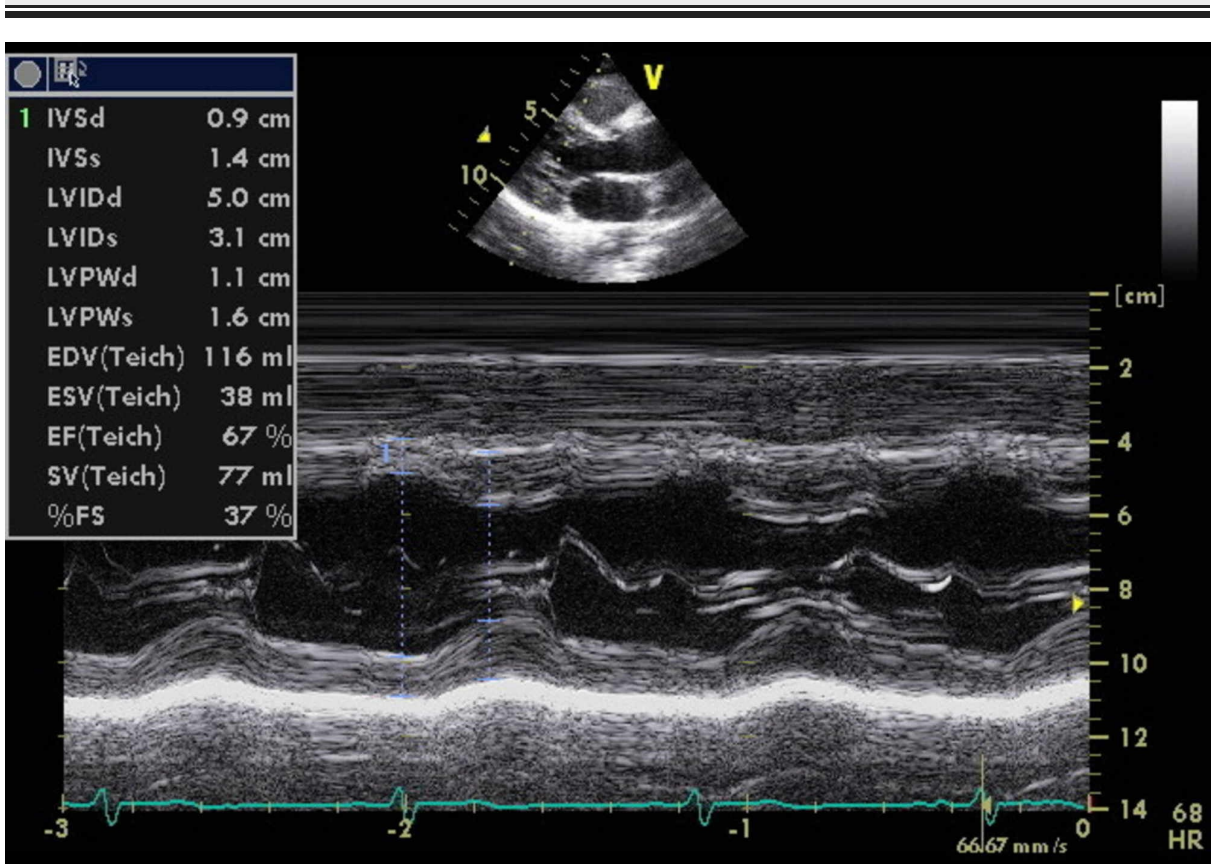

FIGURE 5: Trans-echocardiogram long axis view showing left ventricular thickness is slightly above $1.1 \mathrm{~cm}$.

Treatment 
During the first 24 hours, intravenous labetalol infusion was administered until a target mean arterial pressure of $<110 \mathrm{mmHg}$ was reached; subsequently, treatment was switched to intravenous boluses of labetalol (20 mg) to maintain the same target mean arterial pressure. After the first 24 hours, he was placed on oral amlodipine $(10 \mathrm{mg}$ ) daily and metoprolol $(50 \mathrm{mg})$ every 8 hours. Serial CT brain scans showed no progression of the hemorrhage; therefore, a neurosurgical intervention was not required. The diagnosis of RA was confirmed, and he was started on oral prednisolone $(5 \mathrm{mg})$ daily and methotrexate $(7.5 \mathrm{mg})$ weekly on the 5th day of admission. His BP started to improve after that (Figure 6). He was discharged home with close follow-up with a primary care physician and a rheumatologist. One month after discharge, his joint symptoms were controlled on methotrexate alone, and he was switched on ramipril $5 \mathrm{mg}$ for his HTN, which fairly controlled his BP.

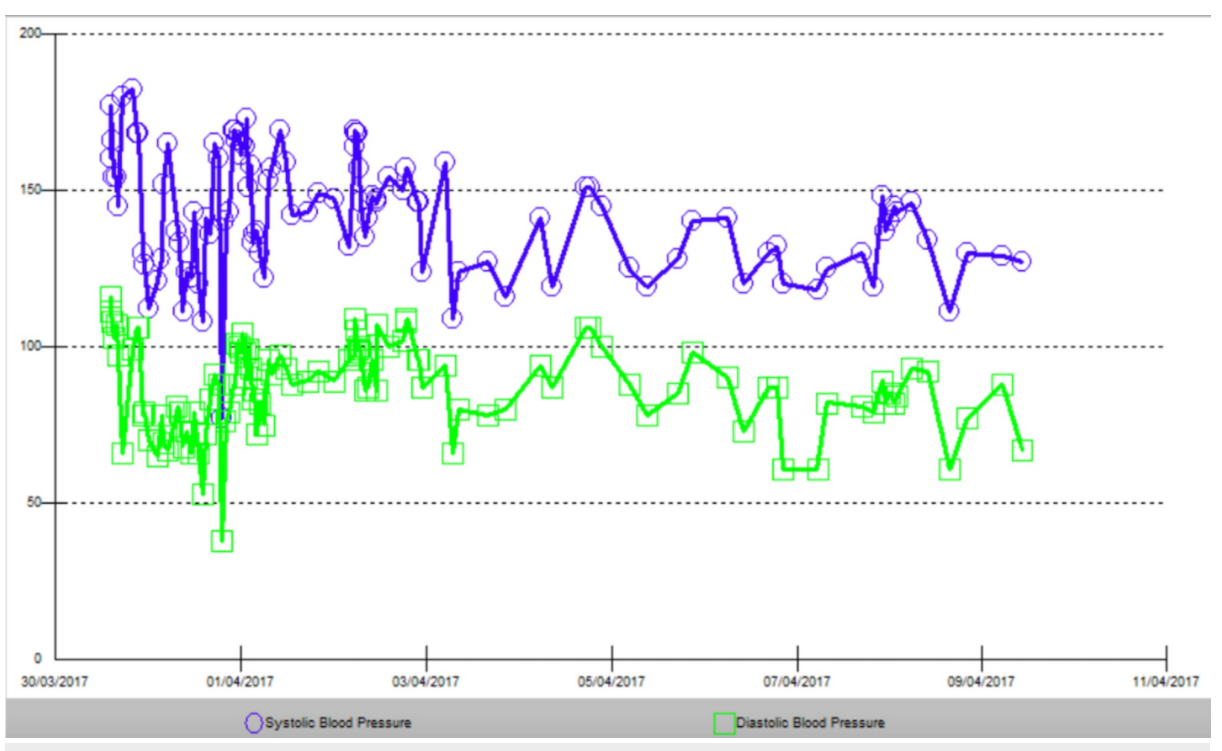

FIGURE 6: Systolic blood pressure and diastolic blood pressure.

\section{Discussion}

It is well established that RA increases the risk of CV events $[1,4]$. After extensive efforts to quantify that risk, we now understand that the relationship is much more complicated than a simple cause and effect phenomenon. There has been a long-standing theory that RA causes intimal injury and arteriosclerosis through an intense inflammatory response [6]. Multiple cross-sectional and retrospective studies have demonstrated a higher prevalence of hypertension in patients with RA than in the general population [7]. Hence, it has become an interesting phenomenon that needs to be explained. Sesso et al. reported in his prospective observational study that C-reactive protein levels are associated with the future development of hypertension, in patients with inflammatory conditions [8]. However, there is little prospective evidence on a temporal relationship between RA, hypertension, and subsequent end-organ damage, including ICH.

Few cases of ICH in patients with RA have been reported in the literature [5]. Recently, two large population-based cohort studies associated various immunological diseases, including RA, with ICH and/or subarachnoid hemorrhage $[3,9]$. Both studies have found that the risk of ICH is higher in RA patients, with the highest risk occurring during the first year of diagnosis of RA. However, both of these studies lacked any structured follow-up and they did not consider various important confounding factors such as body mass index, smoking, blood pressure, and race.

In a meta-analysis of 23 studies, it was found that patients with RA have a risk of hemorrhagic stroke 1.68 times higher than that in normal individuals [4]. The end-organ damage because of hypertension is considered to be more prevalent in patients with rheumatoid arthritis than in the general population [10]. Our patient had developed ICH, although there was no record of BP ever having been above 180/120 $\mathrm{mmHg}$. It is thought that the risk of ICH exponentially increases when BP exceeds $180 / 120 \mathrm{mmHg}$. Hemorrhage rarely occurs when $\mathrm{BP}$ is below that range unless there is a sudden and rapid increase in BP [11]. Other than borderline left ventricular hypertrophy, our patient had no evidence of acute or chronic hypertensive endorgan damage.

The fact that the patient's hypertension had been diagnosed a year prior to his stroke with no evidence of chronic hypertensive end-organ damage, had been controlled on a single oral medication with full compliance, and that a BP greater than $180 / 120 \mathrm{mmHg}$ had never been recorded during his hospitalization, led us to look for another explanation for his susceptibility to ICH. He had no coagulopathies, all immunological markers for vasculitis tested negative, and CT angiogram did not reveal cerebral vasculitic 
lesions or other forms of gross vasculopathy.

Detailed questioning revealed that his six-month history of polyarthralgia was not properly investigated and was undiagnosed. The early subclinical joint inflammation and lack of other physical signs of RA, as well as the normal X-rays of his joints before hospital admission had likely prevented the diagnosis of early RA. He had active RA with high levels of inflammatory markers. Based on the American College of Rheumatology criteria, the diagnosis of RA was established.

The patient was started on oral prednisolone which dramatically controlled his joints symptoms. In addition, his BP could not be controlled with anti-hypertensives until after prednisolone was started on the fifth day of hospitalization (Figure 6).

It has been observed that controlling hypertension in patients with RA can be quite challenging compared with that in the general population. In a cross-sectional study, it was found that optimal control of hypertension in patients with RA was significantly lower at $13.2 \%$ than the $21 \%-23 \%$ observed in the general population [12]. Because inflammation is thought to be a contributing factor in this phenomenon it has been suggested that cardiovascular medications with anti-inflammatory properties, such as angiotensinconverting enzyme inhibitors, exhibit enhanced antihypertensive properties, particularly when administered to patients with RA [12].

Although hypertension is a long-term side effect of the chronic use of oral steroids used for treating RA [13]. It remains unclear to what degree can corticosteroids induce hypertension in patients with RA. It is interesting to note that hypertension in our patient was not perfectly controlled in the hospital until after the fifth day of admission when prednisolone was initiated (Figure o). Although this may have been a coincidence, it might have played a role in controlling the inflammation thereby helping control resistant hypertension observed in patients with RA. This case gave us an opportunity to consider the complex role of inflammatory mediators in RA and their possible effects on BP and cardiovascular diseases.

\section{Conclusions}

It is well known that RA increases the risk of thromboembolic disease, however, a relationship with ICH is not yet well established. If indeed a direct causative link can be made between the inflammatory state in patients with RA and an increased risk of hemorrhagic stroke, it will be interesting to know whether diagnosing and treating RA early in the disease would reduce this risk. It would require further investigations into the pathophysiology of such strokes with regard to inflammatory vasculitis as well as prospective studies on patients with RA to ascertain whether good disease control actually reduces the risk of ICH or any other cardiovascular events. If such an effect can be shown, then reduction of cardiovascular risk in such patients may well begin in the rheumatologist's office.

\section{Additional Information \\ Disclosures}

Human subjects: Consent was obtained by all participants in this study. Conflicts of interest: In compliance with the ICMJE uniform disclosure form, all authors declare the following: Payment/services info: All authors have declared that no financial support was received from any organization for the submitted work. Financial relationships: All authors have declared that they have no financial relationships at present or within the previous three years with any organizations that might have an interest in the submitted work. Other relationships: All authors have declared that there are no other relationships or activities that could appear to have influenced the submitted work.

\section{References}

1. Sokka T, Abelson B, Pincus T: Mortality in rheumatoid arthritis: 2008 update . Clin Exp Rheumatol. 2008, 26:35-61.

2. Del Rincón I, Williams K, Stern MP, Freeman GL, O'Leary DH, Escalante A: Association between carotid atherosclerosis and markers of inflammation in rheumatoid arthritis patients and healthy subjects. Arthritis Rheum. 2003, 48:1833-1840. 10.1002/art.11078

3. Zöller B, Li X, Sundquist J, Sundquist K: Risk of subsequent ischemic and hemorrhagic stroke in patients hospitalized for immune-mediated diseases: a nationwide follow-up study from Sweden. BMC Neurol. 2012, 12:41. 10.1186/1471-2377-12-41

4. Wiseman SJ, Ralston SH, Wardlaw JM: Cerebrovascular disease in rheumatic diseases: a systematic review and meta-analysis. Stroke. 2016, 47:943-950. 10.1161/STROKEAHA.115.012052

5. Watson P: Intracranial hemorrhage with vasculitis in rheumatoid arthritis . Arch Neurol. 1979, 36:58. 10.1001/archneur.1979.00500370088026

6. Crilly MA, Kumar V, Clark HJ, Scott NW, Macdonald AG, Williams DJ: Arterial stiffness and cumulative inflammatory burden in rheumatoid arthritis: a dose-response relationship independent of established cardiovascular risk factors. Rheumatology. 2009, 48:1606-1612. 10.4103/0975-3583.70901

7. Panoulas VF, Douglas KM, Milionis HJ, et al.: Prevalence and associations of hypertension and its control in patients with rheumatoid arthritis. Rheumatology. 2007, 46:1477-1482. 10.1093/rheumatology/kem169

8. Sesso HD, Burning JE, Rifai N, Blake GJ, Gaziano JM, Ridker PM: C-reactive protein and the risk of 


\section{Cureus}

developing hypertension. JAMA. 2003, 290:2945-2951. 10.1001/jama.290.22.2945

9. Rataplan SV, Pakpoor J, Seminog O, Goldacre R, Graham L, Goldacre MJ: Risk of subarachnoid haemorrhage in people admitted to hospital with selected immune-mediated diseases: record-linkage studies. BMC Neurol. 2013, 13:176. 10.1186/1471-2377-13-176

10. Panoulas VF, Toms TE, Metsios GS, et al.: Target organ damage in patients with rheumatoid arthritis: the role of blood pressure and heart rate. Atherosclerosis. 2010, 209:255-260. 10.1016/j.atherosclerosis.2009.08.047

11. Song YM, Sung J, Lawlor DA, Smith GD, Shin Y, Ebrahim S: Blood pressure, haemorrhagic stroke, and ischaemic stroke: the Korean national prospective occupational cohort study. BMJ. 2004, 328:324. 10.1136/bmj.328.7435.324

12. Dandona P, Dhindsa S, Ghanim H, Chaudhuri A: Angiotensin II and inflammation: the effect of angiotensinconverting enzyme inhibition and angiotensin II receptor blockade. J Hum Hyprten. 2007, 21:20-27. 10.1038/sj.jhh.1002101

13. Mazzantini M, Talarico R, Doveri M, Consensi A, Cazzato M, Bazzichi L, Bombardieri S: Incident comorbidity among patients with rheumatoid arthritis treated or not with low-dose glucocorticoids: a retrospective study. J Rheumatol. 2010, 37:2232-2236. 10.3899/jrheum.100461 